Revista de la red interuniversitaria de estudios sobre las literaturas rioplatenses contemporáneas en Francia

11 | 2014

De niños e infancias

\title{
Lecturas de Sergio Chejfec
}

Benoît Coquil

\section{OpenEdition}

Journals

Edición electrónica

URL: http://journals.openedition.org/lirico/1873

DOI: $10.4000 /$ lirico. 1873

ISSN: 2262-8339

Editor

Réseau interuniversitaire d'étude des littératures contemporaines du Río de la Plata

\section{Referencia electrónica}

Benoît Coquil, «Lecturas de Sergio Chejfec », Cuadernos LIRICO [En línea], 11 | 2014, Publicado el 01 diciembre 2014, consultado el 22 septiembre 2020. URL : http://journals.openedition.org/lirico/1873 ; DOI : https://doi.org/10.4000/lirico.1873

Este documento fue generado automáticamente el 22 septiembre 2020

\section{(c) (i) (9)}

Cuadernos LIRICO está distribuido bajo una Licencia Creative Commons Atribución-NoComercialSinDerivar 4.0 Internacional. 


\title{
Lecturas de Sergio Chejfec
}

\author{
Benoît Coquil
}

\section{REFERENCIA}

Dianna C. Niebylski (ed.), Sergio Chejfec : trayectorias de una escritura. Ensayos críticos. Pittsburgh, Instituto Internacional de Literatura Iberoamericana (IILI, Universidad de Pittsburgh), 2012, 320 páginas.

1 Durante los últimos veinte años, la obra de Sergio Chejfec se ha ido afirmando como una de las propuestas literarias más atípicas y estimulantes dentro de la profusa producción narrativa argentina. Sergio Chejfec aparece en la escena literaria al principio de la década del 80 como crítico literario en las revistas Fin de siglo y Pie de página, así como en el suplemento cultural del periódico Tiempo Argentino, entre otros. Por aquella época, Chejfec conoció a Beatriz Sarlo, quien entonces dirigía uno de los "grupos de estudio" reprimidos por la dictadura y quien lo invitó a colaborar a su revista Punto de vista. Chejfec participó luego activamente en la revista Babel (fundada en 1988), cuyos colaboradores apelaban a una renovación en la narrativa nacional, vinculada de manera demasiado directa, según ellos, con los valores nacionales y el compromiso político.

2 Su primera novela, Lenta biografía (1990), que retoma - para mejor subvertirlos - los rasgos del relato autobiográfico, sienta las bases de algunas temáticas que se volverán transversales en toda la obra posterior : los orígenes judíos y el motivo del exilio y de la errancia, las cuestiones de la memoria y de la lengua. El autor descarta luego la escritura del "yo" - que reanudará más tarde, y otra vez de manera oblicua, con Los planetas (1999) y Mis dos mundos (2008) - y publica relatos de ficción que cuestionan incesantemente las convenciones del género novelesco. Los personajes, a menudo anónimos o de identidades inestables, evolucionan por un escenario espacial y temporal poco referencial (en general un espacio urbano marginal, periférico) y la narración se concibe más bien en términos de digresión y fragmento, antes que como una verdadera "trama". Como lo formula el crítico Rafael Castillo Zapata, los textos de 
Chejfec constituyen "relatos de pensamiento, activados a partir de un prolongado soliloquio reflexivo de personajes casi siempre cavilosos, narradores introvertidos que despliegan la anécdota como si se tratara de un acertijo $»^{1}$. Cercanas en esto a la narrativa de Juan José Saer, las obras de Sergio Chejfec, desde El Aire -novela publicada en 1992 que le permitió adquirir más visibilidad en Argentina - hasta su libro de cuentos más reciente, Modo linterna (2013), se asemejan a crónicas de experiencias ontológicas dentro de las cuales los temas del viaje y el vagabundeo, del espacio urbano y de la memoria van tejiendo un complejo sistema de ecos.

3 Si la producción literaria de este autor ha sido objeto de muchos artículos periodísticos, ha suscitado también un número importante de breves ensayos universitarios, tanto en América Latina como en Estados Unidos y Europa. El objetivo de la recopilación ensayística coordinada y editada por Dianna C. Niebylski, profesora de Literatura Latinoamericana y Comparada en la Universidad de Illinois en Chicago, y titulada Sergio Chejfec: Trayectorias de una escritura. Ensayos críticos, es paliar cierta dispersión de los análisis de la obra de Sergio Chejfec, y organizar estos estudios según algunos ejes temáticos fundamentales para la reflexión sobre este escritor. Es, por ahora, el único libro crítico que existe sobre su obra. Los dieciséis ensayos reunidos en el libro y repartidos en cuatro capítulos dan cuenta, mediante la diversidad de perspectivas que proponen, de la riqueza de la narrativa de Chejfec.

4 La detallada introducción, a cargo de Dianna Niebylski, nos ayuda primeramente a situar sus libros en un espectro genérico y en un conjunto de influencias tanto argentinas como europeas. Si algunos textos de Chejfec, empezando por el primero, Lenta biografía, parecen tomar la forma de lo que Dianna Niebylski llama "autobiografía despersonalizada", otros más recientes se acercan al género ensayístico, y muchos se han nutrido del género de la fábula. "Debatiéndose entre el ensayo y la parábola alegórica, las fábulas postmodernas de Chejfec, como las modernas de Kafka o de Borges, descartan de antemano la simple moraleja", escribe la investigadora, citando dos ascendentes mayores para Chejfec. A estos dos nombres Dianna Niebylski agrega, entre otros, los de Juan José Saer, de influencia preponderante en este autor, y del escritor judío-alemán W. G. Sebald. Chejfec comparte con este último, en efecto, un cuestionamiento literario de la identidad judía y, del mismo modo que con Robert Walser, "una concepción de la narración como paseo o vagabundeo". Finalmente, los numerosos personajes de vagabundos, de seres desterritorializados o en situación de "liminalidad" que transitan por la obra de Chejfec hacen ecos, según la autora, a famosos personajes de "extranjeros" o de desplazados de la literatura occidental, sean los de Kafka, de Camus, Musil o Benjamin.

5 En "Chejfec por Sarlo", la crítica y profesora argentina se concentra esencialmente en la novela El aire, y analiza tanto al protagonista como el escenario urbano, que no es solamente el telón de fondo de la narración sino que ocupa un lugar central en el argumento. El personaje de Barroso aparece para Sarlo como cierta reminiscencia del "hombre sin cualidades" de Musil, un hombre que, a partir del momento en que lo abandona su mujer - desaparición que define el punto "revelador que ilumina el espacio cotidiano" y el punto de partida de la novela -, empieza a vagabundear por una ciudad mutante que se "pampeaniza". Sarlo pone aquí de realce la herencia y distorsión del motivo clave de Radiografía de la pampa de Ezequiel Martínez Estrada, ensayo en el cual Buenos Aires está descrita como una urbe que lo invade todo. Donde Martínez Estrada diagnostica un "exceso de ciudad", Chejfec ofrece la visión de un deterioro, una falta. 
Siguiendo con esta hipótesis de una desviación de la tradición literaria en Chejfec, Beatriz Sarlo analiza el libro Mis dos mundos y la nueva imagen del flâneur, del escritor caminante que nos da a ver: "Las revelaciones que, en el pasado, sucedían durante las caminatas (Goethe y Rousseau caminaron sin pausa) no le ocurren [al narrador de Mis dos mundos], como si la era de la revelación hubiera caducado"3.

6 A continuación, Edgardo Horacio Berg insiste, en "Paseo, narración y extranjería en Sergio Chejfec", en la preponderancia del motivo geográfico en la obra del escritor argentino, y en su manifestación como modus scribendi en los textos mismos: "Las bifurcaciones, los saltos en el tiempo, las historias que se fragmentan en microhistorias, la descomposición de los acontecimientos por las pausas reflexivas, siempre aparecen bajo la lógica del traspaso y la metáfora del camino". Originalidad formal y excentricidad de los desplazamientos geográficos se corresponden. Además, Chejfec escenifica a personajes errantes cuyas identidades, bajo el signo de una "extranjería", se revelan sumamente inseguras, frágiles, siempre a punto de borrarse. Abarcando en su estudio un gran número de textos de Chejfec - sin dejar de lado las obras menos estudiadas como Moral, El llamado de la especie o incluso el libro de poemas Gallos y huesos - Edgardo Horacio Berg analiza así el motivo recurrente de la "erosión" de la identidad, y añade una hipótesis sobre el sustrato judaico de este leitmotiv del vagabundeo.

7 Isabel Quintana aborda en "Topografías de la memoria, trazos de afectos y la potencia de la escritura en Lenta Biografía" la estructura, muy particular, de esta primera novela de Sergio Chejfec. Como una estrategia memorial frente al riesgo del olvido y la imposibilidad de contar el trauma pasado - la huida de la Europa nazi por el padre del narrador -, la narración sigue un esquema complejo, aunque reiterativo, que trastoca la convención del género literario anunciado en el título. En vez de una sucesión de hechos vividos, la narración acoge una proliferación de versiones del mismo suceso : el encuentro entre un joven perseguido por los nazis y su padre. El narrador, en vez de tomar la palabra, la delega en varios personajes-narradores que yuxtaponen y discuten los recuerdos. Apoyando su análisis en la lectura de Giorgio Agamben, Isabel Quintana muestra que en Chejfec la memoria no se reconstituye de manera monológica y lineal sino como algo precario e inseguro.

El texto de Dianna Niebylski, "Paralajes de la memoria, desviaciones del duelo y otras ilusiones ópticas en Los planetas", prosigue el estudio del tratamiento de la memoria y del trauma de la desaparición en Chejfec. Los planetas, esta obra clave en la cual el narrador evoca sus recuerdos de un amigo desaparecido durante la dictadura, se afirma como una meditación sobre la pérdida y sobre la poética que conviene elaborar para distanciarse "tanto de la urgencia uni-direccional, acusatoria y restitutiva del testimonio como del registro pasional o psicoanalítico de la escritura del trauma"5. El testimonio aparece completado así por una reflexión sobre su propia forma: por consiguiente, es un testimonio que designa su propia artificiosidad y trata de transcribir el funcionamiento sumamente subjetivo, inseguro y opaco de la memoria. Esto se manifiesta bajo la forma recurrente de las ilusiones ópticas en el texto, pero también en la confusión de las identidades entre el narrador y el amigo desaparecido y en las reflexiones del sobreviviente sobre la imposibilidad de encontrar un registro elegíaco adecuado para decir el duelo. Dianna Niebylski se refiere aquí a los escritos elegíacos de Derrida y a su cuestionamiento del duelo freudiano.

9 Luz Horne postula en "Fotografía y retrato de lo contemporáneo en El aire y otras novelas de Chejfec" que la narrativa de Chejfec se sitúa en la encrucijada entre una 
"ambición realista" de representar una realidad social contemporánea, de pintar un "fresco del presente", y ciertos procedimientos vanguardistas que crean discontinuidades en el relato de esta realidad. Sin embargo, estos recursos propios de la vanguardia no están para Luz Horne al servicio de un mensaje sobre la artificiosidad de la representación y la imposibilidad de la mímesis, sino que precisamente esta "discontinuidad se utiliza (...) como herramienta para construir un relato de lo contemporáneo". Boca de lobo es el libro que interesa a Maximiliano Sánchez ("Ecos de Marx en Boca de lobo"), y en el cual observa ciertas resonancias de los primeros escritos de Karl Marx. Sin embargo el relato se distancia de un discurso ideológico que pueda desembocar en una acción política : los obreros de la fábrica que ve el narrador aparecen atrapados en un tiempo circular, repetitivo, sin escapatoria, enquistados en un "fin de la historia", según la fórmula de Francis Fukuyama ${ }^{7}$. Si la narración tiende a proporcionar la visión de una realidad social, no cesa de designarse como equivocación, como un discurso "incapaz de representar las formas de la verdad". Según Maximiliano Sánchez, el narrador señala incesantemente la ineficacia de la escritura novelística para describir lo singular y concreto : "Boca de lobo se establece, desde esta perspectiva, como una novela que intenta lo imposible: narrar con palabras una historia de cuerpos y de marcas (...) En este sentido, puede afirmarse que, más que una novela, Boca de lobo es la imposibilidad de una novela".

Alejandra Laera, en "Los trabajos : creación y escritura en Boca de lobo y otras novelas de Chejfec", prosigue esta hipótesis y agrega que la previa oposición, presente en el libro de Sergio Chejfec, entre novela y realidad se desplaza a la dicotomía entre escritura y experiencia. Para la investigadora, el texto de Chejfec plantea la duda sobre la vigencia contemporánea del papel de la creación ("entendida en su sentido liberador") como protección o resistencia "frente al trabajo expropiador de las fuerzas del cuerpo".

Para Craig Epplin en "La literatura como producción en Baroni : un viaje", el libro de Chejfec sobre el trabajo artesanal de la escultora venezolana Rafaela Baroni es una meditación sobre qué es o podría ser la obra de arte en el presente, y la obra de literatura en particular. Chejfec parece afirmar que, del mismo modo en que las esculturas de madera de la artista llevan las marcas de su proceso de fabricación, "la obra de arte debe permitir la exhibición del proceso a través del cual emerge. Debe poner de relieve sus rajaduras y su sustrato material frente al espectador" ${ }^{10}$. Esa afirmación sirve también de modus operandi para el escritor que concibe sus objetos literarios como "ensamblaje[s]" de materiales heterogéneos, entre los cuales se insertan varias formas de paratextos (por ejemplo el blog del autor).

En "La confesión de la pobreza. Un cierto Borges en Baroni: un viaje y otras obras de Chejfec", Reinaldo Laddaga tiene como propósito destacar la "constelación borgiana" presente en la obra de Chejfec. Las influencias de Borges (sobre todo el de los primeros poemas, de Luna de enfrente en particular) se notan por ejemplo en cierta visión de la soledad, la pobreza y la ausencia, o en la narración de vagabundeos hacia zonas urbanas indeterminadas, hacia las orillas - fascinación borgiana por antonomasia - que se puede encontrar por ejemplo en Los planetas, El llamado de la especie o El aire. Chejfec hereda así del autor de Ficciones la representación melancólica de "la caminata hacia un espacio fronterizo (...) donde se encuentra menos el fin de lo conocido que un sitio donde lo conocido persiste, pero un poco en hilachas o jirones"1.

14 En el último ensayo, "Entre Sebald y Google : la deriva de Sergio Chejfec", Jorge Carrión acerca la narrativa de Chejfec, basada muchas veces en relatos de vagabundeos, a la de Sebald y de Peter Handke. Pero el investigador subraya también que Chejfec, en su 
reciente libro Mis dos mundos, añade elementos nuevos a la figura tradicional del caminante. Por una parte introduce en este personaje estereotipado cierto desinterés por el lugar por el que transita: si el vagabundeo como adicción "puede llevarnos a Handke y a Sebald, (...) sin embargo, "el desinterés" no tiene intertexto alguno en la tradición mencionada"12. Por otra parte, aparecen alusiones a la informática como herramienta cartográfica y como metáfora del pensamiento en movimiento, por ejemplo con la imagen del enlace de internet. Chejfec se esforzaría así constantemente por renovar tradiciones para hacer de sus textos testimonios del tiempo presente.

En su entrevista con Edgardo Horacio Berg y Nancy Fernández, Sergio Chejfec declaraba : "Soy hijo de extranjeros (...) y en un momento advertí la presencia de un contorno en mi propio país. (...) Diría que me sentía cerca de un borde difuso, que mi naturaleza era ajena a cualquiera de las construcciones ideológicas y discursivas de la argentinidad, pero que sin embargo pertenecía a esta comunidad" ${ }^{13}$. La mayoría de los artículos reunidos en esta compilación tiende a subrayar esta posición atípica, intermedia de Chejfec en el campo literario argentino, rasgo que constituye gran parte del interés de su obra, ya que permite claves de lectura muy diversas : se puede leer a Chejfec desde Borges, desde ciertos escritores contemporáneos de lengua alemana (Walser, Sebald), desde otros escritores argentinos que han emergido en la época de la revista Babel, etc. Si la multiplicidad de los abordajes críticos presentados aquí permite tener una visión precisa de la riqueza de la narrativa de este autor, esperamos que esta visión sea completada por nuevos artículos sobre las obras de Chejfec menos estudiadas (tales como Moral, El llamado de la especie y Cinco) y las más recientes (La experiencia dramática y Modo linterna, ambas publicadas en 2013).

\section{NOTAS}

1. castillo Zapata, Rafael, «El relato metafórico de Sergio Chejfec », Cuadernos Hispanoamericanos, n⿳o 617, Madrid, 2001.

2. Niebylski, Dianna C., "Introducción : Sergio Chejfec : De Lenta biografía a Mis dos mundos", in Niebylski, Dianna C. (ed.), Sergio Chejfec: trayectorias de una escritura. Ensayos críticos. Pittsburgh, 2012, p. 24-25.

3. Sarlo, Beatriz, « Chejfec por Sarlo», in Niebylski, Dianna C. (ed.), op. cit., p. 42.

4. Berg, Edgardo Horacio, "Paseo, narración y extranjería en Sergio Chejfec", in Niebylski, Dianna

C. (ed.), op. cit., p. 45-46.

5. Niebylski, Dianna C., "Paralajes de la memoria, desviaciones del duelo y otras ilusiones ópticas en Los planetas", in Niebylski, Dianna C. (ed.), op. cit., p. 102.

6. Horne, Luz, "Fotografía y retrato de lo contemporáneo en El aire y otras novelas de Chejfec", in Niebylski, Dianna C. (ed.), op. cit, p. 126.

7. Fukuyama, Francis, El fin de la historia y el último hombre, Barcelona, Planeta, 1992.

8. Sánchez, Maximilano, "Ecos de Marx en Boca de Lobo", in Niebylski, Dianna C. (ed.), op. cit, p. 198.

9. Laera, Alejandra, "Los trabajos : creación y escritura en Boca de lobo y otras novelas de Chejfec", in Niebylski, Dianna C. (ed.), op. cit, p. 212. 
10. Epplin, Craig, "La literatura como producción en Baroni : un viaje", in Niebylski, Dianna C. (ed.), op. cit., p. 247.

11. Laddaga, Reinaldo, "La confesión de la pobreza", in Niebylski, Dianna C. (ed.), op. cit., p. 280.

12. Carrión, Jorge, "Entre Sebald y Google", in Niebylski, Dianna C. (ed.), op. cit, p. 291.

13. Berg, Edgardo Horacio y Fernández, Nancy, "Fuera de lugar : entrevista a Sergio Chejfec", in Celehis : Revista del Centro de Letras Hispanoamericanas, Universidad Nacional de Mar del Plata, núm. 11 (1999), p. 319-322.

\section{AUTORES}

\section{BENOÎT COQUIL}

Université Stendhal - Grenoble 3 